\title{
A life cycle assessment of the environmental impacts of a beef system in the USA
}

\author{
Senorpe Asem-Hiablie ${ }^{1}$ (D) Thomas Battagliese $^{2} \cdot$ Kimberly R. Stackhouse-Lawson $^{3} \cdot$ C. Alan Rotz ${ }^{1}$
}

Received: 8 July 2016 / Accepted: 7 March 2018 / Published online: 30 May 2018

(C) The Author(s) 2018

\begin{abstract}
Purpose The need to assess the sustainability attributes of the United States beef industry is underscored by its importance to food security locally and globally. A life cycle assessment (LCA) of the US beef value chain was conducted to develop baseline information on the environmental impacts of the industry includ ing metrics of the cradle-to-farm gate (feed production, cowcalf, and feedlot operations) and post-farm gate (packing, case-ready, retail, restaurant, and consumer) segments.

Methods Cattle production (cradle-to-farm gate) data were obtained using the integrated farm system model (IFSM) supported with production data from the Roman L. Hruska US Meat Animal Research Center (USMARC). Primary data for the packing and case-ready phases were obtained from packers that jointly processed nearly $60 \%$ of US beef while retail and restaurant primary data represented 8 and $6 \%$, respectively, of each sector. Consumer data were obtained from public databases and literature. The functional unit or consumer benefit $(\mathrm{CB})$ was $1 \mathrm{~kg}$ of consumed, boneless, edible beef. The relative environmental impacts of processes along the full beef value chain were assessed using a third party validated BASF Corporation Eco-Efficiency Analysis methodology.

Results and discussion Value chain LCA results indicated that the feed and cattle production phases were the largest contributors to most environmental impact categories. Impact metrics included water emissions ( $7005 \mathrm{~L}$ diluted water eq/CB), cumulative energy demand $(1110 \mathrm{MJ} / \mathrm{CB})$, and land use $\left(47.4 \mathrm{~m}^{2} \mathrm{a} \mathrm{eq} / \mathrm{CB}\right)$. Air emissions were acidification potential $\left(726 \mathrm{~g} \mathrm{SO}_{2} \mathrm{eq} / \mathrm{CB}\right)$, photochemical ozone creation potential $\left(146.5 \mathrm{~g} \mathrm{C}_{2} \mathrm{H}_{4} \mathrm{eq} / \mathrm{CB}\right)$, global warming potential $(48.4 \mathrm{~kg} \mathrm{CO} 2 \mathrm{eq} / \mathrm{CB})$, and ozone depletion potential $\left(1686 \mu \mathrm{g} \mathrm{CFC}_{11} \mathrm{eq} / \mathrm{CB}\right)$. The remaining metrics calculated were abiotic depletion potential (10.3 $\mathrm{mg}$ $\mathrm{Ag}$ eq/CB), consumptive water use $(2558 \mathrm{~L}$ eq/CB), and solid waste (369 g municipal waste eq/CB). Of the relative points adding up to 1 for each impact category, the feed phase contributed 0.93 to the human toxicity potential.

Conclusions This LCA is the first of its kind for beef and has been third party verified in accordance with ISO 14040:2006a and 14044:2006b and 14045:2012 standards. An expanded nationwide study of beef cattle production is now being performed with region-specific cattle production data aimed at identifying region-level benchmarks and opportunities for further improvement in US beef sustainability.
\end{abstract}

Responsible editor: Peter Rudolf Saling

Electronic supplementary material The online version of this article (https://doi.org/10.1007/s11367-018-1464-6) contains supplementary material, which is available to authorized users.

Senorpe Asem-Hiablie senorpe.ah@gmail.com

1 Pasture Systems and Watershed Management Research Unit, US Department of Agriculture-Agricultural Research Service, University Park, PA 16802, USA

2 BASF Corporation, 100 Park Avenue, Florham Park, NJ 07932, USA

3 Formerly of National Cattlemen's Beef Association, 9110 East Nichols Ave., Suite 300, Centennial, CO 80112, USA
Keywords Beef footprints $\cdot$ Beef production emissions $\cdot$ Beef sustainability $\cdot$ Beef value chain

\section{Introduction}

Meeting growing and changing consumer demands while minimizing negative environmental and social impacts is a current challenge facing beef as well as other livestock industries. The USA is currently the world's largest beef-producing country raising close to $20 \%$ of the world's annual supply with $10 \%$ of the world's cattle population (USDA-FAS 2015). Environmental impacts and resource use have been studied for various segments of the US beef value chain, but a comprehensive cradle-to-grave life cycle assessment (LCA) has 
not been completed (Dudley et al. 2014; Ghafoori et al. 2006; Lupo et al. 2013; Pelletier et al. 2010; Roop et al. 2014; Stackhouse-Lawson et al. 2012). As one of the most complex food systems in the world, a comprehensive LCA of beef is particularly challenging.

A nationwide LCA was initiated under the US Beef Sustainability Research Program to establish baseline impact metrics and identify areas for improvement along the beef value chain. Primary cradle-to-farm gate inventory data were obtained from the Roman L. Hruska US Meat Animal Research Center (USMARC; the largest agricultural animal research facility in the USA) as modeled and supported by the integrated farm system model (IFSM; USDA-ARS, University Park, PA). The IFSM is a process-level whole-farm simulation model used to evaluate environmental impacts of dairy and beef production systems (Rotz et al. 2006, 2012). The model has been evaluated and used to represent operations of varying sizes, landscapes, and climates (Belflower et al. 2012; Chianese et al. 2009a, b; Corson et al. 2007; Deak et al. 2010; Ghebremichael and Watzin 2011; Salim et al. 2005; Sedorovich et al. 2007; Stackhouse-Lawson et al. 2012; Stackhouse et al. 2012; Waldrip et al. 2014). The relative environmental impacts of processes along the full beef value chain were assessed using a third party validated BASF Corporation (BASF SE, Ludwigshafen, Germany) EcoEfficiency Analysis (EEA) methodology based on the International Organization for Standardization (ISO 2006a) 14040 standards (Saling et al. 2002; Uhlman and Saling 2010).

\subsection{Goal and scope definition}

The overall goal of this LCA was to provide a baseline of the environmental impacts of current practices along the US beef value chain. The specific aim was to quantify the sustainability impacts associated with the production and consumption of $1 \mathrm{~kg}$ of consumed beef for a representative system in the USA. The target audience included the beef industry and its stakeholders, consumers, and public.

The scope of this study was a cradle-to-grave assessment of the sustainability of a US beef supply chain. Environmental impacts of the beef value chain were evaluated in terms of the cradle-to-farm gate (feed production, cow-calf, and feedlot operations) and post-farm gate (packer, case-ready, retail, consumer, and restaurant) segments. Impacts of the production of resource inputs such as fertilizer and packaging were included. While cattle production data were farm-specific, packing and other post-farm gate data were representative of the entire US beef industry. Cattle production data were obtained from USMARC because of the extensive high-quality data available. Their production system followed commercial practices.

\subsection{Functional unit}

The functional unit was defined for the purposes of this study as the consumer benefit (CB), a unit of which was $1 \mathrm{~kg}$ of consumed, boneless, edible beef in the USA. This represented an average of all beef cuts, i.e., the impact allocated to meat was divided by the total of all edible beef obtained. Boneless beef was chosen in order to evaluate beef-specific impacts. The dressing percentage (carcass yield) at harvest was based on industry averages of $62 \%$ for finished cattle and $50 \%$ for culled cows and bulls. Accounting for losses at the packing and case-ready phases from fat and bone removal and shrink (33\%), retail phase losses from shrinkage and spoilage (7\%), and consumer phase losses from cooking, spoilage, and plate waste $(20 \%)$ resulted in $29 \%$ as the portion of live weight consumed as edible beef (Table 1). Therefore, a live weight of $3.45 \mathrm{~kg}$ resulted in $1 \mathrm{~kg}$ of consumed beef. Percentage losses were obtained from USDA-ERS (2012a) and primary data as shown in Table 1. That not consumed was treated as by-products or handled as waste where a small portion of the various impacts was allocated to by-products.

\section{Methods}

The life cycle EEA of beef was performed using the BASF methodology (BASF SE, Ludwigshafen, Germany), which follows ISO 14040:2006a and 14044:2006a standards for LCAs and ISO 14045:2012 for EEA. The analysis was
Table 1 Yield of carcass from live animal (dressing percentage) and value chain losses used in calculating the functional unit (consumer benefit) in US beef life cycle impact assessment

\begin{tabular}{lcl}
\hline Description & Percent & Source \\
\hline Dressing percentage, finished cattle & 62 & USDA-ERS (2012a) \\
Dressing percentage, cull cattle & 50 & USDA-ERS (2012a) \\
Losses in packing and case-ready phases (fat, bone, and shrink) & 33 & USDA-ERS (2012a) \\
Loss in retail phase (fat, bone, shrink) & 7 & Primary retail data \\
Loss in consumer phase (cooking losses, spoilage, plate waste) & 20 & USDA-ERS (2012a) \\
Portion of live weight consumed as edible beef & 29 & Calculated \\
\hline
\end{tabular}

${ }^{\mathrm{a}}$ Twenty-four percent of beef comes from cull animals with $76 \%$ from finished cattle 
validated and verified by NSF International under Protocol P352 Parts A (BASF 2013a) and B (BASF 2015), respectively. Data sources included reported and IFSM-simulated cattle production data (Rotz et al. 2013), life cycle inventory databases, public databases, expert opinion, and primary processing and use data. Environmental impact was measured by the following metrics: consumption of non-renewable raw materials or abiotic depletion potential (ADP), cumulative energy demand (CED), consumptive water use (CWU), land use, and human toxicity potential (HTP) of materials used. Air, solid waste, and water emissions were also quantified. Air emissions included acidification potential (AP), global warming potential (GWP), ozone depletion potential (ODP), and photochemical ozone creation potential (POCP). Particulate matter was not included in the current study due to lack of industry data, complexity in characterization, and resulting unavailability of standard LCA procedures. Figure 1 shows a schematic of the main components of the life cycle impact analysis. Summaries of the data and sources are provided in related tables and the Supplementary Information.

\subsection{System boundaries}

Figure 1 shows a schematic of the system boundaries of the life cycle impact analysis. Cattle originating as cull animals from the dairy industry as well as beef imports and exports were not included in the production system. Feed imports were also excluded as all feed was produced within the USMARC production system. Of the total national major feed grains supply reported by the USDA-ERS (2017) which included use for other livestock species as well as food and industrial uses, less than $12 \%$ was imported at the time of this study. Capital, equipment, buildings, infrastructure, and materials for repairs and maintenance were excluded from the study as they are not usually included in LCAs of agricultural commodities, goods, and services due to their insignificant effects. Impacts that contributed $<1 \%$ individually as specific components or unit operations or $<3 \%$ in total as a group of components or processes to the overall value chain were generally excluded from the LCA. Among these were office and administrative impacts, employee commutes, cattle veterinary

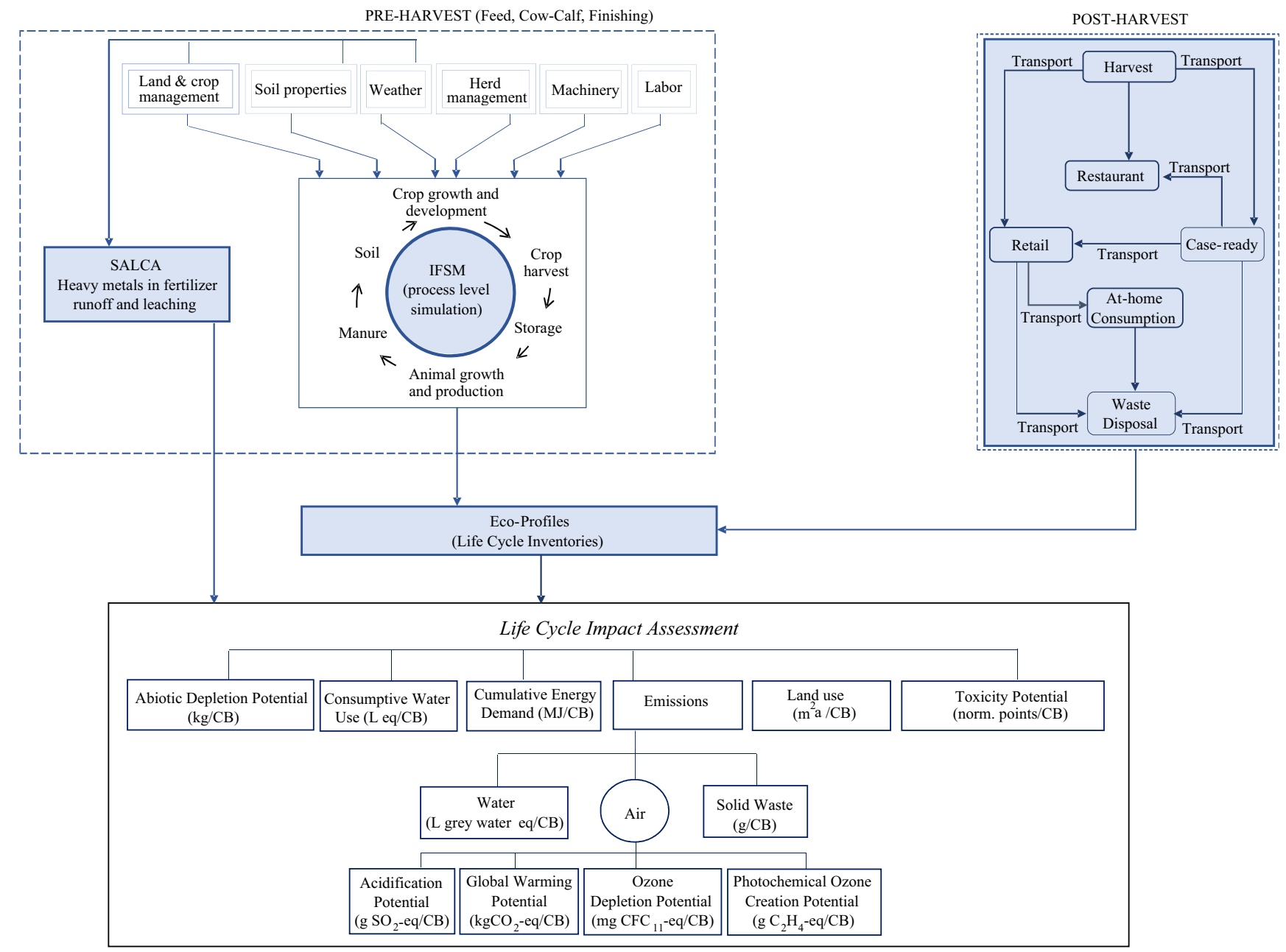

Fig. 1 An overview of the US beef life cycle analysis including inputs and outputs of phases, and impacts measured 
medicines, and retailer and consumer use of cleaning compounds.

\subsection{Data sources and input information}

Required inventory data included resource use and emissions for feed and cattle production and packing, case-ready, retail, restaurant, and consumer phases. Feed and cattle primary data were developed through reports of the USMARC and simulation of its production system (Rotz et al. 2013). This research facility provided high-quality and extensive management data that were difficult to obtain otherwise from the industry. The crop, feed, and animal management practices of this facility were characteristic of those practiced in the Great Plains (this region stretches north to south of the central USA and encompasses western Texas and eastern New Mexico through North Dakota and eastern Montana) where most cattle are produced. An exception to this similarity was greater irrigation use at the USMARC to grow feed crops and pasture compared to the rest of the industry. Another difference, albeit negligible when considering environmental impact, was a greater labor involvement in production at this federal research facility. Due to the region-specific nature of production practices across the USA resulting from differences in climate, available resources, and culture, the USMARC facility is not meant to represent all beef production systems in the nation. It does, though, provide a general representation of beef cattle production in the USA.

Biological and physical processes of the beef cattle production system were simulated with the IFSM, and the predicted performance of the operation was found to agree well with production records of the research center (Rotz et al. 2013). The full operation was simulated as three components: feed production, cow-calf production, and feedlot finishing. The accuracy of the IFSM predictions for feed production and use, energy use, and production costs (within 1\% of reported values in 2011) justified its use for this study (Rotz et al. 2013). The USMARC and IFSM simulations primarily provided resource and farm input data as well as direct emissions in feed and cattle production from which life cycle inventories were derived.

The post-farm gate assessment consisting of the packing, case-ready, retail, restaurant, and consumer phases, used primary data from industry and information from public databases, literature review, and when necessary expert opinion. Various data were collected between 2011 and 2013. All feed, cattle, and packing phase data were representative of 2011 management practices, while primary retail and restaurant data were from 2013. Case-ready data from study partners were from 2011 and 2013. Specific details of the sources of input data are given in the relevant sections below. Impacts of resource use and emission outputs were quantified using life cycle inventories of inputs, processes, and outputs of each phase. The inventories were compiled from primary industry data, the BASF life cycle inventory database, Boustead Model Version 5.1.2600.2180 (Boustead 2005), and Ecoinvent Version 2.2 (Frischknecht et al. 2005).

All primary data obtained from packing plants, case-ready, and restaurants were obtained by providing each study partner with spreadsheets listing all inputs going into the system for which they provided the input values. The details of all primary data cannot be listed for confidentiality reasons. Neither can the extensive inventory of materials and resources from BASF's database used in this study because this would be impractical and this also has propriety concerns. This paper's intention is to provide sufficient detail and to adhere to quality standards required for dissemination of findings to stakeholders and the interested public. Therefore, the study underwent critical review by a third party, NSF International, and is reported as Protocol P352 Parts A (BASF 2013a) and B (BASF 2015). Through this peer review process, the study was verified and approved as valid.

\subsubsection{Feed production}

The feed production phase studied the life cycle of feed produced and purchased for cattle consumption at the USMARC. Based on year 2011 records, the USMARC produced feed crops on 2108 ha of irrigated land and maintained 9713 ha of unirrigated pasture to feed the cattle produced. Feed crops included alfalfa/grass hay and silage, corn silage, high moisture corn, and dry corn grain. Feed purchased to supplement the farm's production included $1790 \mathrm{t}$ (dry matter) of wet distiller's grain (WDGS). Crop growth, feed utilization, and nutrient cycling were simulated with IFSM using daily weather conditions on the crop farm during the study period (Rotz et al. 2013). Resource utilization, operation timeliness, crop losses, and feed quality were predicted based on reported tillage, planting, harvesting, and storage practices. Nutrient flows traced through the farm predicted environmental losses including reactive nitrogen $\left(\mathrm{NH}_{3}, \mathrm{NO}_{3}{ }^{-}\right.$, and $\mathrm{N}_{2} \mathrm{O}$ ), phosphorous, and net greenhouse gas $\left(\mathrm{CO}_{2}, \mathrm{CH}_{4}\right.$, and $\left.\mathrm{N}_{2} \mathrm{O}\right)$ emissions. Emission factors obtained from IFSM simulations directly related to crop production and additional field emissions derived using recommendations of the Intergovernmental Panel on Climate Change (IPCC 2006) are presented in Table 2. Cattle manure used to fertilize the farm and pastureland was generated within the USMARC and therefore had no associated pre-chain impacts. Rotz et al. (2013) provide a detailed description of the USMARC facility and IFSM simulations. Land use change impacts on greenhouse gas emissions can be substantial in areas where forests are transformed into farms for feed crop production. As cattle feed in the USA are not typically sourced from such areas, land use change was not considered as an important contributor to the GWP in this study. 
Table 2 Emission rates from fertilizer and manure application on feed crops used in US beef life cycle impact assessment

\begin{tabular}{|c|c|c|}
\hline Emission type & Rate & Source \\
\hline \multirow[t]{2}{*}{ Runoff loss (corn fields only) } & $0.15 \mathrm{~g} \mathrm{P} / \mathrm{kg} \mathrm{P}$ applied & IFSM simulation \\
\hline & $0.60 \mathrm{~g} \mathrm{~N} / \mathrm{kg} \mathrm{N}$ applied & IFSM simulation \\
\hline Air emissions (direct + corn crop residue) & $0.20 \mathrm{~g} \mathrm{~N}_{2} \mathrm{O} / \mathrm{kg}$ applied & IFSM simulation \\
\hline $\mathrm{N}$ fertilizer leaching & $30 \%$ of $\mathrm{N}$ applied & IPCC (2006) \\
\hline Leached $\mathrm{N}$ to $\mathrm{N}_{2} \mathrm{O}-\mathrm{N}$ & $0.75 \%\left(2.25 \mathrm{~kg} \mathrm{~N}_{2} \mathrm{O}-\mathrm{N}^{\mathrm{a}} / \mathrm{kg}\right.$ fertilizer $\mathrm{N}$ applied $)$ & IPCC (2006) \\
\hline $\mathrm{CO}_{2}$ from urea & $200 \mathrm{~g} \mathrm{CO}_{2}-\mathrm{C}^{\mathrm{b}} / \mathrm{kg}\left(\mathrm{NH}_{2}\right)_{2} \mathrm{CO}$ applied & IPCC (2006) \\
\hline $\mathrm{CO}_{2}$ from limestone & $120 \mathrm{~g} \mathrm{CO}_{2}-\mathrm{C} / \mathrm{kg} \mathrm{CaCO}_{3}$ applied & IPCC (2006) \\
\hline Volatilization of $\mathrm{NH}_{3}$ from fertilizer- $\mathrm{N}$ & $100 \mathrm{~g} \mathrm{NH}_{3} / \mathrm{kg} \mathrm{N}$ applied & IPCC (2006) \\
\hline
\end{tabular}

${ }^{\mathrm{a}} \mathrm{N}_{2} \mathrm{O}-\mathrm{N}=$ annual direct $\mathrm{N}_{2} \mathrm{O}-\mathrm{N}$ emissions produced from soil amendment (urea or limestone) decomposition, $\mathrm{kg} \mathrm{N} \mathrm{N}_{2} \mathrm{O}-\mathrm{N} / \mathrm{year}$

${ }^{\mathrm{b}} \mathrm{CO}_{2}-\mathrm{C}$ emission = annual $\mathrm{C}$ emissions from soil amendment (urea or limestone) decomposition, $\mathrm{kg} \mathrm{C} / \mathrm{year}$

Purchased corn for WDGS was ascribed Ecoinvent profiles (Table S1, Electronic Supplementary Material) representative of the Iowa corn-belt region which unlike the USMARCcultivated corn was not irrigated. The average transportation roundtrip distances assumed for purchased corn to the distillery for WDGS production were $400 \mathrm{~km}$ and that of WDGS from the distillery to the USMARC was $32 \mathrm{~km}$. As WDGS is a by-product of corn-based bioethanol distillation, an economic allocation was used to determine its impacts. This was done by deducting the drying energy from the life cycle inventory of $1 \mathrm{~kg}$ of dried distiller grains with solubles (DDGS) and multiplying the weight of the DDGS by 1.55 (Bonnardeaux 2007) to reflect the weight of WDGS. The bioethanol profile was adjusted to represent Iowa corn production yields, and the WDGS profile was created by allocating $21 \%$ of the distillation process and pre-chain impacts based on economic allocation using ethanol, WDGS, and DDGS pricing which were US $\$ 0.54 / \mathrm{kg}$, US $\$ 0.09 / \mathrm{kg}$, and US $\$ 0.24 / \mathrm{kg}$ at the time of the study.

The chemical oxygen demand (COD) for pesticides (Table S1, Electronic Supplementary Material) was calculated using their chemical formula ( $\mathrm{C}, \mathrm{O}, \mathrm{N}$, and $\mathrm{H}$ stoichiometry). Runoff and leaching emissions of heavy metals, including those from fertilizer application, were obtained using the Swiss Agricultural Life Cycle Assessment (SALCA) Heavy Metals calculator (Freiermuth 2006). As SALCA did not include options for selecting US specific soil characteristics, German values were substituted to simulate representative heavy metal dynamics (such as heavy metal percolation, deposition, and leaching rates) in the soil. This assumption was not seen to have a meaningful impact in the results as the representative soil type used was similar to US agricultural soils.

Irrigation was used to produce all feed crops and some pasture on the USMARC operation. Irrigation-associated impacts included CWU sourced from on-farm wells with a small amount (1\%) from surface water. Electricity and natural gas were both used to pump water through center pivot irrigation systems, and pre-chain impacts for their production and use were included.

\subsubsection{Cattle production}

Cattle production, consisting of cow-calf and feedlot operations, followed the life cycle of cattle from birth to harvest. In 2011, USMARC maintained 5050 calves, 5498 cows, 285 bulls, and 1180 replacement heifers in the cow-calf operation and 3724 cattle were finished in the feedlot (Rotz et al. 2013). In the cow-calf operation, cattle were grazed on pasture (a small part of which received irrigation) and fed hay and silage during winter. Weaned calves were moved to a feedlot where they received a high-forage backgrounding diet of hay and distiller's grain for 3 months and then were put on a highgrain finishing diet of corn grain, corn silage, and distiller's grain for another 7 months. At 16 months of age, cattle were harvested with an average weight of $581 \mathrm{~kg}$. Also included in the harvest were cull cows and bulls from the cow-calf phase of the operation (Rotz et al. 2013).

Supplementary feed was accounted for in this phase, whereas all grazed and harvested forage and grains were included in the feed production phase. Enteric $\mathrm{CH}_{4}$ and $\mathrm{CH}_{4}$, $\mathrm{N}_{2} \mathrm{O}$, and $\mathrm{NH}_{3}$ emissions from excreted feces and urine and phosphorous and nitrogen runoff losses from pastureland were simulated with the cattle operations. Drinking water was supplied by USMARC wells, which accounted for the consumptive water used by the livestock. Energy used for pumping drinking water and its associated pre-chain impacts was also accounted for in this phase.

Transportation of calves and cows within USMARC operations was minimal with no effect on the LCA's results. Generally, transportation impacts have been found to be relatively low in beef cattle systems in the USA even when cattle were transported over long distances (Rotz et al. 2015). The minor effect of cattle transportation to the packing plant was included in the packing phase. 
Enteric $\mathrm{CH}_{4}$ emitted by cattle was the only form of biogenic carbon included in the analysis. The carbon in the enteric $\mathrm{CH}_{4}$ emitted was assumed to be assimilated from $\mathrm{CO}_{2}$ in the atmosphere during crop growth. To account for the assimilation and avoid double counting, a $1 \mathrm{CO}_{2}$ eq credit was applied to the global warming potential (GWP) factor of $\mathrm{CH}_{4}$ (thus utilizing a GWP of $24 \mathrm{CO}_{2}$ eq for methane as opposed to the standard factor of $25 \mathrm{CO}_{2} \mathrm{eq}$ ). The major inputs for the cattle phase's life cycle inventory are shown in Table S2 (Electronic Supplementary Material).

\subsubsection{Packing}

The packing phase of the value chain processes live animals into edible beef. Primary and calculated input data describing operational emissions and waste (Table S3, Electronic Supplementary Material) were obtained from site visits and interviews with three packers who collectively processed $60 \%$ of the US beef harvested annually. For equity in representation, the packers studied represented both small and largescale operations and their weighted averages (based on weight of beef processed by each size of operation) were used. Primary transportation data for cattle, packaging (paper and plastics), liquid $\mathrm{CO}_{2}$, and wastes of the packing phase were used, and their average transport distance of $2033 \mathrm{~km}$ was assigned to all other raw materials and supplies. The byproducts of beef (including hides, offal, blood, tallow, bones, and bone meal) received an economic allocation of $11.7 \%$ of the production and packing impacts based on primary sales data obtained from the collaborating packers. The COD emissions (Table S3, Electronic Supplementary Material) were calculated using the $\mathrm{C}, \mathrm{O}, \mathrm{N}$, and $\mathrm{H}$ stoichiometry of the relevant compounds.

End-of-life impacts of $96 \%$ of each packaging material (plastic and corrugated cardboard packaging containing 30\% recycled fiber) were assigned to the case-ready or retail phase as these materials entered either phase directly from the packing phase whose waste profile received the remaining $4 \%$ of the packaging plastics' end-of-life impacts. The remaining $4 \%$ of corrugated cardboard was recycled and had no further impacts attributed to it following cutoff allocation rules.

\subsubsection{Case-ready}

The case-ready phase further processes primal cuts of beef into consumer-ready packaged cuts. Based on data from the case-ready study partners, $63 \%$ of US beef was assumed to be packaged in the case-ready phase. Primary data were obtained from a packer with a case-ready operation and a stand-alone case-ready operation (Table S3, Electronic Supplementary Material). Input data were also received from a collaborating packer with case-ready operations where energy input, packaging, consumable items, and waste were directly reported.
For water use and cleaning chemicals, input values were assumed to be $10 \%$ of the reported use of the packing facilities based on knowledge of this facility's operators and industry experts. End-of-life impacts of $96.5 \%$ of the packaging material were attributed to the retail or consumer phases. The study boundary did not include the $3.5 \%$ of corrugated cardboard that was recycled (following cutoff allocation rules).

\subsubsection{Retail}

The retail phase represented distribution and marketing of beef to the consumer. Primary data (Table S4, Electronic Supplementary Material) were obtained from three retailers ranging in size and representing $8 \%$ of the total retailed US beef. As the retail operations included sales other than beef, an economic allocation was performed based on the ratio of beef to total store sales. For refrigerated sales, allocations of refrigerant leakage and electricity use were refined using averages of ICF (2005), USEPA (2011, 2012), and FMI (2012) data.

\subsubsection{Consumer}

The consumer phase included consumer impacts from transportation to the retail store and beef consumption at home. Transportation considered the ratio of beef to total supermarket purchases, and cooking was based on the average beef cooking preference of the consumer in relation to the average energy required to cook $1 \mathrm{~kg}$ of consumed beef while considering the percentages of electric or gas stoves. Public information and data gathered from literature were used to calculate national averages of consumer-phase inventory inputs (Table S4, Electronic Supplementary Material) related to consumer repackaging of beef, transportation (USDOT 2011), refrigeration electrical energy consumption (AHAM 2011), cooking energy (USEIA 2005), and beef waste (USDA-ERS $2012 b$ ). Volumetric allocation based on the typical US consumer's diet (considered to consist of $12.7 \%$ meat by volume) followed by the application of economic purchasing factors to derive the beef portion of meat consumed was used to allocate impacts related to consumer beef refrigeration (USDA-ERS 2005).

\subsubsection{Restaurant}

The restaurant phase studied impacts of beef sold to consumers in restaurants and used primary data from quickservice and casual sit-down restaurants representing nearly $6 \%$ of US beef sold in restaurants. As restaurants typically sell other consumables in addition to beef, an economic allocation factor calculated as the ratio of beef sold to total restaurant sales was used. It was also assumed that 53 and $47 \%$ of US beef consumption were in restaurants and at home, respectively, based on industry data (Meat Solutions, Inc. 2014). System 
inputs in the restaurant phase are listed in Table S5 (Electronic Supplementary Material).

\subsubsection{Recycling and waste}

Packaging of beef was assumed to be done either in the caseready phase (for sale at retail) or by the retailer. Footprints of the $30 \%$ recycled fiber in the corrugated cardboard used by most of the post-farm facilities surveyed were obtained from pre-defined profiles in Ecoinvent which also took into consideration the item's production processes and appropriate allocations. Of post-farm packaging other than cardboard, disposal was assumed to be 82 and $18 \%$ in landfills and incinerators, respectively, with energy recovered from that incinerated (USEPA 2010). Additionally, a modified Ecoinvent profile was given to waste packaging disposed in municipal and solid waste landfills to remove accounting for contaminants such as heavy metals that were originally part of the municipal waste Ecoinvent profile but not found in beef packaging waste. While all direct waste generated at each phase of the value chain was evaluated based on its final fate and degradation after emissions to water and air, solid waste associated with the production of resource inputs was assessed based on its final disposal (i.e., recycling, incineration, or landfilling). Finally, the cutoff method was applied for impacts from incineration, as the impacts from incineration were assumed to be attributed to the energy consumer (i.e., purchaser of the electricity generated from incineration).

\subsection{Environmental impact metrics}

Abiotic depletion potential $(\mathrm{kg} \mathrm{Ag} \mathrm{eq} / \mathrm{CB})$ measured the effects of raw material use on the availability of natural reserves. As described by Uhlman and Saling (2010), the mass of basic raw materials from each resource needed to manufacture a product was weighted by a factor consisting of the quantity of each material's geologic reserves and life span as defined by the USGS (Guinée et al. 2002) given current global extraction rates for all uses. Thus, materials with lower reserves and/ or higher consumption rates received higher weightings. Sustainably managed renewable resources had a weighting factor of " 0 " to indicate infinite reserves. Information on demand and available reserves were obtained from national mineral commodity statistics (USGS 2012) and fossil energy reserve data (BP 2012). Table S6 (Electronic Supplementary Material) provides a list of essential raw materials considered, their global reserves, and assigned weighting factors.

Cumulative energy demand $(\mathrm{MJ} / \mathrm{CB})$ was the sum of all energy needed for the production, use, and disposal of a product as well as the energy content of the product. All individual energy sources (e.g., biomass, coal, lignite, natural gas, nuclear, oil, and wind) measured in $\mathrm{MJ} / \mathrm{CB}$ were summed to obtain the CED per CB. As electricity companies use an assortment of fuels to generate electricity, a life cycle inventory was assembled for each type contributing to the national grid. The contribution of each fuel type to the national grid was based on the 2011 US Energy Information Administration's data on electricity generation by energy source. Losses during the conversion of electrical energy to steam and line losses of electricity were included. The gross bioenergy content of feedstock (energy released through combustion of feed biomass) was included but not the solar energy required for its production. The gross bioenergy for corn silage, corn grain, alfalfa silage and hay, and grass from managed and natural pastures ranged from 17.8 to $18.6 \mathrm{MJ} / \mathrm{kg}$ dry matter (Ecoinvent Version 2.2; Frischknecht et al. 2005). No weighting factors were applied to the CED.

Consumptive water use $(\mathrm{L}$ eq/CB) quantified withdrawn freshwater lost from the watershed of origin in a product's life cycle via evaporation, absorption into products and waste, or transfer out of the watershed (Pfister et al. 2009). Water stress indices (WSIs) obtained from Pfister et al. (2009) and served as midpoint characterization factors applied to the volume of absolute CWU ( $\mathrm{L}$ abs/CB) to obtain the CWU (L eq/CB). Coefficients defining absolute CWU represented the consumptive fraction of the water used in a given process and were taken as midpoint ranges from USGS consumptive water data (Solley et al. 1998). These included cropping (70\%), livestock (55\%), industrial (25\%), and thermoelectric power $(50 \%)$. For example, in crop production, $100 \mathrm{~L}$ of water used for irrigation was $70 \mathrm{~L}$ absolute consumed (70\% loss to evapotranspiration and runoff from the watershed) multiplied by the water stress index of 0.499 giving an equivalent of $35 \mathrm{~L}$ eq/ CB.

Human toxicity potential (dimensionless) quantified possible toxic effects of material exposure on human health prechain, along the value chain, and material disposals within study boundaries (Landsiedel and Saling 2002). The production, use, and disposal of all materials relevant to the beef value chain were inventoried and assigned scores between 0 and 1000 based on hazard statements (H-phrases) from safety data sheets according to the Globally Harmonized System of Classification and Labelling of Chemicals (Table S7, Electronic Supplementary Material; adapted from Landsiedel and Saling 2002). Based on expert opinion, the scores were further modified, normalized, and weighted considering exposure conditions, substance's persistence, and exposure risk as described in BASF (2013a). The sum of the products of the quantities of each substance used and their calculated scores was found. Finally, materials were assigned weightings of 20, 70 , and $10 \%$, based on the possibility of exposure at the production, use, and disposal phases, respectively. Pre-chain Hphrases were considered in the production phase of resource inputs only. The heaviest weighting of $70 \%$ was assigned to "use" as it is at this stage that the highest risk of personal exposure was expected. When a substance's use occurred as 
part of its production and no disposal occurred because it was used up with the value chain, an integration of the weighting factors yielded a value " 100 "; thus, weighting was irrelevant.

Land use $\left(\mathrm{m}^{2} \mathrm{a}\right.$ eq/CB, where $\mathrm{a}=$ time in years) was considered in terms of both occupation and change (transformation). A series of occupations taking place at different time periods made up the transformation. Land use was calculated as the total area of land and the degree of development required to provide the $\mathrm{CB}$. The degree of land development was based on the ecosystem damage potential (EDP) which was assigned based on the level of occupation or transformation and provides indicators of biodiversity as estimated from the species richness of vascular plants (Koellner and Scholz 2008). Categories of land use occupations and transformations from one use type to another were described by the EDP (Table S8, Electronic Supplementary Material; Frischknecht et al. 2005) following an established BASF methodology. The land use classes included native vegetation, arable, permanent crop, pasture and meadow, urban, industrial, mineral extraction site, traffic areas, dump sites, and water areas.

Air emissions had four main categories (Table S9, Electronic Supplementary Material). Acidification potential ( $\mathrm{kg} \mathrm{SO} \mathrm{SO}_{2}$ eq) included $\mathrm{SO}_{\mathrm{x}}, \mathrm{NO}_{\mathrm{x}}, \mathrm{NH}_{3}$, and $\mathrm{HCl}$ emissions (Saling et al. 2002). Global warming potential $\left(\mathrm{kg} \mathrm{CO}_{2}\right.$ eq) included anthropogenic $\mathrm{CO}_{2}, \mathrm{CH}_{4}, \mathrm{~N}_{2} \mathrm{O}$, and halocarbons (HC), with each gas adjusted by their 100-year GWP (Forster et al. 2007; IPCC 2006). Ozone depletion potential of $\mathrm{HC}$ was reported as $\mathrm{kg}$ CFC eq. Photochemical ozone creation potential considered those emissions responsible for ground-level ozone, including non-methane volatile organic compounds (NM-VOC) and $\mathrm{CH}_{4}$ measured in $\mathrm{kg} \mathrm{C}_{2} \mathrm{H}_{2}$ eq (Heijungs et al. 1992).

Solid waste impact (kg municipal waste eq/CB) considered materials disposed in a landfill or incinerated. These materials were placed in five categories based on their potential environmental effects. The categories were municipal waste, hazardous waste (as defined by the Resource Conservation and Recovery Act), construction waste (non-hazardous waste materials generated during building or demolition), mining (nonhazardous earth or overburden generated during raw materials extraction), and radioactive waste (as defined by the International Atomic Energy Agency). Existing life cycle inventories provided waste information for the production of resource inputs, while the inventory for the value chain was developed from the primary waste profile data provided by industry partners. As there were no standardized assessment criteria at the time of this study, individual impacts were weighted by the normalized average disposal cost of each waste category in a landfill compiled internally by BASF (Table S10, Electronic Supplementary Material) and then summed to an overall solid waste impact. Any special waste categories from mining raw material inputs were treated according to the specific category's requirements, while the non- hazardous waste (mainly earth) stayed on site for fillings and therefore were assigned a disposal cost of zero (Table S10, Electronic Supplementary Material).

Water emission (L diluted water eq/CB) was based on critical volumes defined as the contaminant concentration multiplied by a dilution factor (the reciprocal of a regional regulatory maximum emission concentration) for each contaminant (Table S11, Electronic Supplementary Material). Total volumes of water discharged from wastewater treatment plants and directly to surface waters were considered. The contaminants included in the BASF EEA method were $\mathrm{NH}_{4}{ }^{+}$, total-N, and $\mathrm{PO}_{4}{ }^{3-}$, as well as heavy metals, hydrocarbons (including detergents and oils), and $\mathrm{SO}_{4}{ }^{2-}$. Also included were $\mathrm{Cl}^{-}$, adsorbable organically bound halogens, and COD. In order to determine total water emissions, the sum of all critical volumes was found and then normalized to aid aggregation of all parameters into a single value (Saling et al. 2002).

\subsection{Qualitative uncertainty and sensitivity analyses}

All data sources used for this study were ranked as high (primary data) to medium (literature review and industry average) quality. The feed, cow-calf, and finishing phases were analyzed with primary data obtained from USMARC and IFSM simulations and were ranked as high to medium quality. Although observed farm environmental data were unavailable with which to make model comparisons of impact metrics, proper modeling of production systems in IFSM has been shown in previous studies to produce accurate predictions of emissions (Rotz et al. 2006, 2010; Stackhouse-Lawson et al. 2012). The IFSM simulations of feed production over local weather conditions, energy use, and production costs fell within $1 \%$ of reported values (Rotz et al. 2013).

Both the packing and case-ready phase data were ranked as high quality. The retail and restaurant data were primary; however, economic allocations were done resulting in a high to medium-quality classification. Data for the consumer phase was described as medium quality having been taken from literature and industry reports. A review of the system inputs showed data to be complete and representative of current industry practices; thus, no critical uncertainties were identified so as to impact the study's results and conclusions.

Sensitivity analyses were done to account for specific integrated processes along the value chain. Three alternative scenarios were studied independently and compared with the base analysis. For two scenarios, analysis of wet distiller's grains by mass allocation (scenario 1) and energy allocation (scenario 2) was compared to the economic allocation used in the base analysis. In a third scenario, analysis of consumer refrigeration by economic allocation (scenario 3) was compared to the volumetric allocation of the base analysis. 


\section{Results and discussion}

Over the full value chain, cattle production impacts dominated with the feed production, cow-calf, and finishing phases having the most influence on a majority of the environmental categories. In a similar study assessing the life cycle impacts of Australian red meat exported to the USA, Wiedemann et al. (2015) also observed that the feed and cattle phases had the highest environmental impacts and resource use. Levels of impacts of either feed or cattle phases were highest for 10 of the 12 environmental metrics (Fig. 2 and Table 3).

\subsection{Resource use}

Metrics related to resource use included ADP, CED, CWU, and land use. On a weighted basis, $\mathrm{Zn}$ use in the animal phase as an essential mineral had the greatest ADP. While the ADP of $\mathrm{Zn}$ appears minor at $6.2 \mathrm{mg} \mathrm{Ag} \mathrm{eq} / \mathrm{CB}$, the prevailing rates of extraction of $\mathrm{Zn}$ in relation to economically available global reserves were high enough to be considered of substantial impact. Fossil energy in the form of natural gas, oil, and coal used for fertilizer production, utilities, and transportation collectively followed $\mathrm{Zn}$ in ADP (Fig. 3). Uranium also showed some importance. All other minerals including phosphorus had a relatively low contribution to ADP. The ADP estimated for the entire beef value chain was $10.3 \mathrm{mg} \mathrm{Ag} \mathrm{eq} / \mathrm{CB}$.

It was estimated that 80.3 and $0.6 \%$ of the calculated total value chain CED (1100 MJ/CB) were bio-based renewable and non-bio-based renewable energy, respectively, while non-renewables made up $19.1 \%$. The majority of the CED $(80 \%)$ was associated with the gross bioenergy of the animal feed. The bio-energy of the major feeds (corn, corn silage, alfalfa, and grass) ranged between 17.8 and $18.6 \mathrm{MJ} / \mathrm{kg}$ dry matter (Ecoinvent 2.2; BASF, 2015). As this energy is a biological necessity for the animals, opportunities for energy reductions would have to be explored in other energy types. Of the fossil energy consumed along the value chain, the highest quantities were used by the restaurant and consumer phases, largely due to the high energy needs for transportation, refrigeration, and cooking. Smaller impacts of the packing and caseready phases on the environmental metrics rose from combustion in electricity production, on-site boiler use, and pre-chain emissions of packaging material (corrugated cardboard and low density polyethylene (LDPE)) production.

The CWU estimate was $2558 \mathrm{~L}$ eq/CB based on a water stress index of 0.499 , while the absolute CWU was $5126 \mathrm{~L} \mathrm{eq} /$ CB (Table 3). Most of the CWU (98\%) went into irrigating feed crops (Fig. 2). Other minor contributors to CWU were the restaurant phase $(0.55 \%)$ and pre-chain water consumption, particularly in the production of electricity and corrugated cardboard. To reduce CWU, more efficient use of irrigation must be adopted to reduce the amount of water withdrawn to meet crop needs. Greater use of non-irrigated pasture and rangeland, increased cropping efficiency, and incorporation of by-products such as distiller's grains in cattle feed are practices that could contribute to reduced irrigation requirements.

Land use was highest at the feed production phase requiring $97 \%$ of the total land area of $47.4 \mathrm{~m}^{2} \mathrm{a}$ eq/CB assessed for the value chain (Table 3 and Fig. 2). Major land users were pasture (which required $31.5 \mathrm{~m}^{2} \mathrm{a}$ eq/CB or $69 \%$ of the $97 \%$ ) and crop land required for animal feed production. Pre-chain cardboard packaging production also made small contributions in terms of land use for tree growth. Total weighted land use may decline through increased crop and pasture yields allowing greater feed production per unit of land area. Packaging optimization may also reduce the trees needed and the fossil fuel extraction required in pre-chain production both leading to reduced land use.

\subsection{Emissions}

The assessed values of the various air emission subcategories were AP (726 $\left.\mathrm{g} \mathrm{SO}_{2} \mathrm{eq} / \mathrm{CB}\right)$, GWP (48.4 $\left.\mathrm{kg} \mathrm{CO}_{2} \mathrm{eq} / \mathrm{CB}\right)$, POCP (146.5 $\left.\mathrm{g} \mathrm{C}_{2} \mathrm{H}_{4} \mathrm{eq} / \mathrm{CB}\right)$, and ODP $\left(1686 \mu \mathrm{g} \mathrm{CFC}_{11}\right.$ eq/
Fig. 2 Percentage contributions of the various phases to each measured environmental impact of beef production and consumption

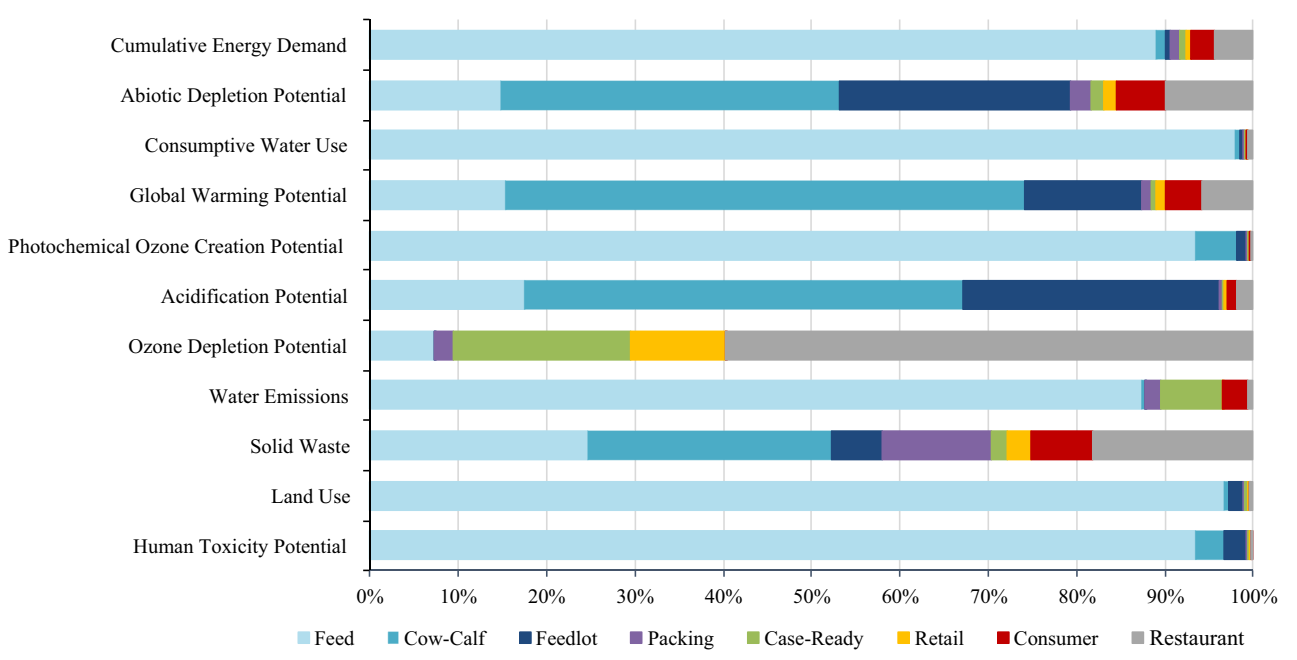


Table 3 Environmental impact metrics quantified in the life cycle assessment of US beef where 1 unit of consumer benefit (CB) is equivalent to $1 \mathrm{~kg}$ of consumed, boneless, edible beef in the USA

\begin{tabular}{|c|c|c|c|c|c|c|c|c|c|c|}
\hline \multirow[t]{2}{*}{ Impact } & \multirow[t]{2}{*}{ Units } & \multicolumn{8}{|l|}{ Phase } & \multirow{2}{*}{$\begin{array}{l}\text { Total beef } \\
\text { value chain }\end{array}$} \\
\hline & & Feed & Cow-calf & Finish & Packing & Case ready & Retail & Consumer & Restaurant & \\
\hline Abiotic depletion potential & mg Ag eq/CB & 1.51 & 3.95 & 2.68 & 0.24 & 0.16 & 0.14 & 0.59 & 1.01 & 10.3 \\
\hline Cumulative energy demand & $\mathrm{MJ} / \mathrm{CB}$ & 988.0 & 11.6 & 6.0 & 11.4 & 8.3 & 6.6 & 29.3 & 48.4 & 1110 \\
\hline Consumptive water use & $\mathrm{L}$ eq/CB & 2506 & 11.9 & 11.2 & 3.7 & 1.9 & 1.7 & 6.8 & 14.0 & 2558 \\
\hline $\begin{array}{l}\text { Absolute consumptive } \\
\text { water use }\end{array}$ & $\mathrm{L}$ abs./CB & 5023 & 23.9 & 22.5 & 7.5 & 3.9 & 3.4 & 13.7 & 28.1 & 5126 \\
\hline Human toxicity potential & norm.tox.pts. & 0.93 & 0.034 & 0.027 & 0.003 & 0.002 & 0.001 & 0.001 & 0.002 & 1.0 \\
\hline Land use & $\mathrm{m}^{2} \mathrm{a}$ eq/CB & 45.8 & 0.3 & 0.7 & 0.1 & 0.2 & 0.0 & 0.1 & 0.2 & 47.4 \\
\hline Acidification potential & $\mathrm{g} \mathrm{SO}_{2} \mathrm{eq} / \mathrm{CB}$ & 127.4 & 359.2 & 210.7 & 2.6 & 1.7 & 2.3 & 7.8 & 13.9 & 726 \\
\hline Global warming potential & $\mathrm{kg} \mathrm{CO}{ }_{2} \mathrm{eq} / \mathrm{CB}$ & 7.42 & 28.51 & 6.39 & 0.55 & 0.27 & 0.46 & 2.01 & 2.83 & 48.4 \\
\hline Ozone depletion potential & $\mu \mathrm{g} \mathrm{CFC}_{11} \mathrm{eq} / \mathrm{CB}$ & 121.4 & 0.1 & 1.4 & 36.9 & 336.6 & 180.7 & 0.9 & 1008 & 1686 \\
\hline $\begin{array}{l}\text { Photochemical ozone } \\
\text { creation potential }\end{array}$ & $\mathrm{g} \mathrm{C}_{2} \mathrm{H}_{4} \mathrm{eq} / \mathrm{CB}$ & 136.9 & 6.8 & 1.8 & 0.2 & 0.2 & 0.1 & 0.2 & 0.4 & 146.5 \\
\hline Solid wastes & $\begin{array}{l}\text { g municipal waste } \\
\text { eq/CB }\end{array}$ & 91.3 & 101.4 & 21.5 & 45.1 & 7.0 & 10.1 & 25.3 & 67.3 & 369 \\
\hline Water emissions & $\begin{array}{l}\text { L diluted water } \\
\text { eq/CB }\end{array}$ & 6127 & 17.9 & 2.4 & 126.1 & 484.9 & 2.2 & 198.8 & 45.9 & 7005 \\
\hline
\end{tabular}

CB) (Table 3). Manure and urine excretions and feed crop fertilization were responsible for the high AP (primarily $\mathrm{NH}_{3}$ emission) of the cow-calf, finishing, and feed phases with contributions of 50,29, and $18 \%$, respectively. Other major AP contributors were emissions from fossil fuel combustion related to electricity production, on-site boiler use at packing plants, transportation, and pre-chain impacts from corrugated cardboard production.

Greenhouse gas emissions at the farm gate have been the most reported of US beef cattle environmental impacts. Studies by Dudley et al. (2014), Lupo et al. (2013), and Pelletier et al. (2010) in the Central, Northern Great Plains, and Upper Midwest USA, respectively, estimated values in
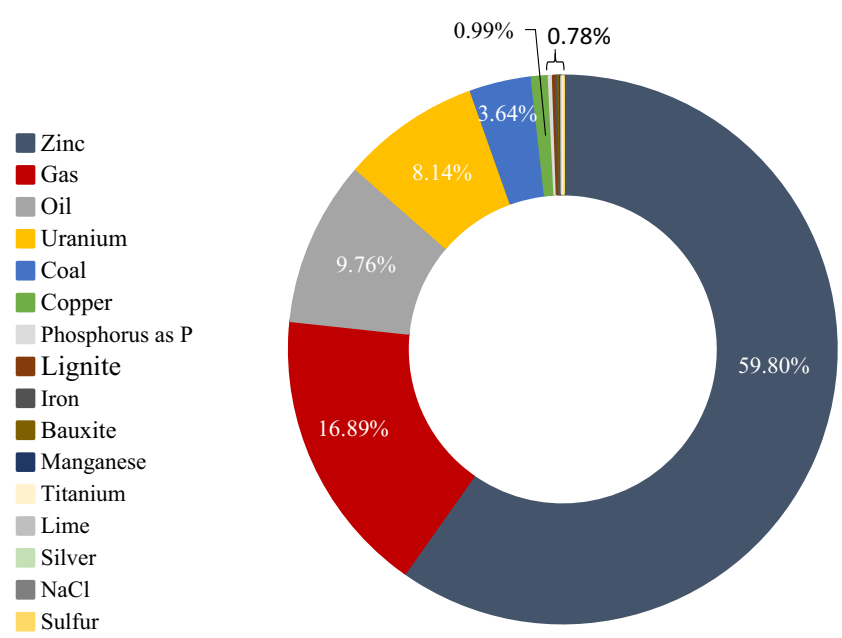

Fig. 3 Abiotic depletion potential (ADP) by resource included in the US beef life cycle assessment the ranges of $8.14 \mathrm{CO}_{2} \mathrm{eq} / \mathrm{kg}$ live weight $\left(14.8 \mathrm{CO}_{2} \mathrm{eq} / \mathrm{kg}\right.$ carcass weight) to $16.2 \mathrm{CO}_{2} \mathrm{eq} / \mathrm{kg}$ live weight $(29.5 \mathrm{~kg}$ $\mathrm{CO}_{2} \mathrm{eq} / \mathrm{kg}$ carcass weight). Roop et al. (2014) reported greenhouse gas emissions for beef cattle production and processing in the Pacific Northwest as $18.8 \pm 0.86 \mathrm{~kg} \mathrm{CO}$ eq $/ \mathrm{kg}$ packaged beef. The range in values is a result of the differences in system types and modeling assumptions. In our study, the cradle to farm gate GWP was within the range of other published studies at $10.9 \mathrm{~kg} \mathrm{CO}$ eq/ $\mathrm{kg}$ live weight or $18.5 \mathrm{~kg}$ $\mathrm{CO}_{2}$ eq/kg carcass weight (Rotz et al. 2013).

Enteric $\mathrm{CH}_{4}$ emission from cattle production was the leading contributor (47\%) to total GWP of the value chain. In a farm gate impact analysis, Pelletier et al. (2010) also estimated that approximately $42 \%$ of greenhouse gases emitted by maintaining beef cattle on pasture was attributable to enteric $\mathrm{CH}_{4}$ emissions while 37 and $21 \%$, respectively, were from feed production and manure emissions. The next highest contributor to the total GWP was $\mathrm{N}_{2} \mathrm{O}(27 \%)$ produced from manure on pastureland, fertilized crop land, and feedlots. Refrigerant leakage at the retail and restaurant phases and cooking at the restaurant and consumer phases together contributed nearly $10 \%$ to the total GWP (Table 3).

The photochemical ozone creation potential (POCP) was most influenced by volatile organic carbon (VOC) emissions from fermented feeds including silage, high moisture corn grain, and distiller's grain primarily fed to cattle on feedlots. Enteric $\mathrm{CH}_{4}$ emissions from the cattle phases also contributed, but this contribution was low due to the relatively low reactivity of $\mathrm{CH}_{4}$.

In the feed production phase, increased crop yields resulting in decreased fertilizer application and lesser 
emissions from fertilizer pre-chain production as well as overall higher production efficiency per hectare of feed might decrease AP and GWP. Greater use of distiller's grain can decrease AP but will likely increase ADP, GWP, and ODP. Moreover, feeding distiller's grain allows beneficial use of a by-product resulting in reductions in natural resources used which bodes well for CWU, land use, and emissions to water while providing environmental benefits outside of the beef value chain.

Ozone depletion potential was primarily associated with post-farm gate processes. The greatest contributor was the restaurant phase with $60 \%$ of ODP (Table 3). The use of halogenated hydrocarbons in the restaurant, case-ready, and retail phases and pre-chain emissions related to the production of LDPE and vinyl gloves contributed most to the ODP.

The feed phase accounted for $90 \%$ of total value chain emissions to water, which was estimated as $7005 \mathrm{~L}$ diluted water eq/CB (Fig. 1 and Table 3). Contributors were 34\% from nitrogen runoff and leaching, 33\% from heavy metal runoff and leaching, and 19\% from phosphorous runoff. Minor water emissions also came from pastureland runoff and leaching. Wastewater from packing and case-ready phases, pre-chain corrugated cardboard production impacts, and landfill leachate from waste disposal contributed notably to post-farm phase water emissions. The highest pollutant load to water arises from feed production; hence, increased efficiency in fertilizer and pesticide use is recommended to reduce runoff and leachate losses. Greater use of by-product and waste-product feeds may also reduce water emissions by reducing feed crop production.

The estimated solid waste impact per CB of beef was $369 \mathrm{~g}$ municipal waste eq, and this was mainly from production of resource inputs as direct wastes generated within the value chain were analyzed according to their final degradation. A major contributor to the solid waste value was pre-chain production of dicalcium phosphate used in cattle feed supplements. Others were related to the production of electricity and the main transport fuels, diesel, and gasoline. The contribution of the pre-chain production of inputs at each phase to the solid waste generated are shown in Fig. 2 and Table 3.

\subsection{Human toxicity}

The feed production phase accounted for $93.0 \%$ of the total value chain HTP, while the cow-calf and finish phases each contributed 3.4 and $2.7 \%$, respectively (Fig. 2 and Table 3). The main HTP contributors were the manufacturing and impacts of fertilizer and pesticide application. Production of resource inputs and value chain fossil energy (coal, diesel, and natural gas) use were also major contributors. Technological improvements that enhance fertilizer use efficiency may reduce fertilizer needs, while reduced fossil fuel use would provide HTP reductions.

\subsection{Sensitivity analyses}

Distiller's grain has come to be an important feed for cattle production; therefore, the procedure used to allocate impacts between the by-products in ethanol production was given further consideration. The base analysis used an economic allocation which assigned $21 \%$ of the bioethanol distillation environmental burden to WDGS. As an alternative, a mass allocation was used which placed $62 \%$ of the environmental burden on WDGS based on a distillation conversion ratio of $479 \mathrm{~kg}$ WDGS to $299 \mathrm{~kg}$ bioethanol (or $378 \mathrm{~L}$ bioethanol, given bioethanol's density is $0.79 \mathrm{~kg} / \mathrm{L}$ ). This increased the burden placed on the feed phase. Total value chain impacts included a $4 \%$ increase in GWP (Fig. 4a) and a 53\% increase in water emissions (Fig. 4b). Energy content allocation was also considered, and this also resulted in $21 \%$ of the bioethanol distillation environmental burden being attributed to WDGS (Lory et al. 2008). One of the main reasons economic allocation was chosen for calculating impacts of WDGS was because this approach was used for by-products in the harvesting phase and therefore provided consistency. Furthermore, using existing pricing, the economic allocation scenario was further supported by the energy allocation as resulting impacts of both approaches proved to be the same.

Allocation effects were also determined for the burdens of retail and consumer refrigeration and retail refrigerant leakage. Volumetric allocation was originally chosen following ISO standards which gave preference to a physical allocation providing representation was logical and data were available. The use of economic allocation showed a 3\% increase in GWP (Fig. 4c) due to the increased impact of refrigerant leakage as well as a $2 \%$ increase in the total value chain CED compared to volumetric allocation (Fig. 4d). However, as the weighted impact of the retail and consumer environmental metrics was not high, little change was observed in the total environmental impacts of the value chain.

\subsection{Impact reduction opportunities}

Many opportunities exist for reducing the environmental impacts throughout the life cycle of beef. A thorough evaluation and ranking of opportunities is beyond the scope of this current analysis, but these results do give some insight toward the more important or effective possible strategies. The primary sources or contributors vary greatly among the metrics used to quantify impact. Therefore, the most promising opportunities for reducing life cycle impacts depends upon the one or more metrics considered to be most important or their ranking in importance.

When extrapolating these data to other production systems and regions, importance will vary among the metrics considered. For example, some regions (Midwest and Eastern USA) are wetter than others (Western USA) and thus require less 
Fig. 4 Environmental impacts of different EEA scenarios for beef. a GWP determined using economic (base) and mass allocation of WDGS (scenario 1). b Water emissions using economic (base) and mass allocation of WDGS (scenario 1). c GWP using volumetric (base) and economic allocation for consumer refrigeration (scenario 3). d CED using volumetric (base) and economic allocation for consumer refrigeration (scenario 3)
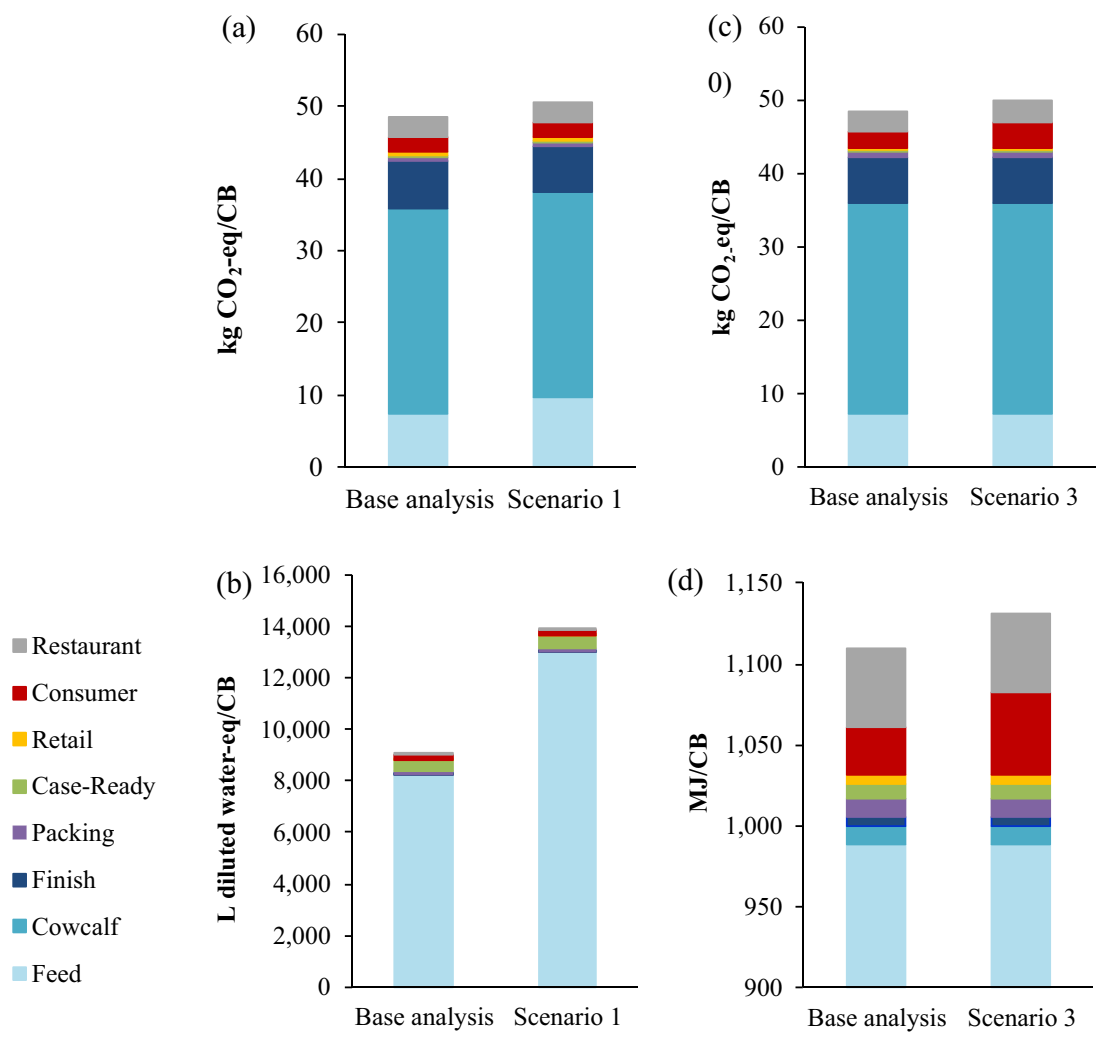

water use; however, leaching and runoff of nutrients are higher for the former (Asem-Hiablie et al. 2015, 2016, 2017). In regions with large dairy herds where cull dairy calves are incorporated into the beef herds, allocation of impacts of the breeding herd to dairy reduces the environmental footprints of the beef produced (Capper 2011; Stackhouse-Lawson et al. 2012; Rotz et al. 2015). Clearly, each region has its own unique opportunities for improvements. Ongoing studies are using regional data to further identify these opportunities (Rotz et al. 2015).

Of the 11 metrics considered in our current analysis, feed production was the major contributor in six (Fig. 2). In each of these, feed production contributed about $90 \%$ or more of the total life cycle impact. Thus improvements in feed production and use appear as an important opportunity. A specific opportunity is to increase crop and pasture yields to obtain more feed per unit of land. Improvement in the efficiency of fertilizer and pesticide use would reduce the need for these resources as well as reduce their losses to the environment. Less dependence upon irrigation or more efficient irrigation strategies in crop and pasture production could greatly reduce CWU with some reduction in water emissions. Reduced tillage in crop establishment would reduce runoff and the associated loss of nutrients; however, the USMARC production system already uses minimum tillage practices.

Cattle are a major contributor in three of the remaining impact categories (ADP, GWP, and AP, Fig. 2). Cattle's impact on ADP is primarily due to the feeding of zinc supplement. Thus, more efficient use of this supplement can reduce this impact. Global warming potential primarily results from the production of enteric methane and secondarily from nitrous oxide and methane emissions from manure. Acidification potential primarily results from ammonia emissions from cattle manure. More efficient cattle production reduces both of these potentials. Maintaining breeding stock for a full year to obtain a calf contributes a large portion of these impacts. Thus, increasing calving rate and reducing death loss are potential benefits. Improving the rate of gain to finish cattle in a shorter period is of benefit because cattle impacts are directly related to the length of their life cycle. Closely related is an improvement in feed efficiency to obtain more gain per unit of feed consumed. More efficient feeding of protein can also reduce the nitrogen excreted by cattle, which will reduce ammonia and nitrous oxide emissions. Alternative cattle housing and manure handling practices can reduce emissions, but these major changes would not be economically viable for most producers. For example, use of a free-stall barn with an enclosed manure storage and subsurface injection of manure may greatly reduce ammonia, nitrous oxide, and methane emissions, but use of this technology would greatly increase the cost of production compared to the use of an open feedlot.

Post-farm gate processes are a predominate source of impact in only 2 of the 11 metrics considered (ODP and solid waste, Fig. 2). Reduction in ODP can be obtained primarily through reduced use and emission of halogenated 
hydrocarbons, primarily in the restaurant sector. This would include reduced loss of refrigerants and less use of aerosols. Solid waste is well distributed across all phases of the beef life cycle. Benefits would be received through less waste of the beef product and more efficient use and recycling of packaging materials.

Recent improvements at the post-farm phases offer opportunities for further modest decreases in the overall value chain impacts (BASF 2013b). In the packing phase, biogas generation and recovery from wastewater lagoons and switching from fuel oil to natural gas use are reducing direct fossil energy use and impacts associated with the production of resource inputs that contribute to CED, ADP, GWP, POCP, AP, solid waste generation, and land use.

Packaging optimizations in the packing and case-ready phases are also reducing packaging (corrugated cardboard and LDPE) needs, transportation requirements, landfill wastes, as well as related pre-chain processes, which result in reduced CED, ADP, CWU, GWP, POCP, ODP, ADP, water emissions, and land use. Recent improvements in water use efficiency at the packing phase and case-ready phase packaging optimizations also contribute to declines in water use (BASF, 2013b). Further adoption of these and other practices can improve the sustainability of beef.

\section{Conclusions}

In this environmental assessment of a US beef full value chain system, the feed and cattle phases contributed the greatest impacts in most categories studied. Feed production accounted for $90 \%$ or greater of water emissions, POCP, HTP, land use, CWU, and CED. Improved crop yields and more efficient use of fertilizer, pesticides, and other resource inputs will help mitigate these impacts. Greater use of byproduct feeds may also lower impacts of the feed phase. However, feeding of by-products should be well managed to prevent impacts such as increased $\mathrm{NH}_{3}$ and $\mathrm{N}_{2} \mathrm{O}$ emissions from overfeeding protein.

The cow-calf and finishing phases had the highest AP due to $\mathrm{NH}_{3}$ emission from cattle feces and urine. Ammonia from fertilizer application in the feed phase also contributed significantly. Abiotic resource use was highest at the cow-calf and finishing phases primarily due to the feeding of $\mathrm{Zn}$ supplements. The majority of the remaining ADP was attributed to fossil energy used to produce fertilizers and fuel for utilities and transportation.

The feed and cattle phases contributed substantially to CED and GWP through bio-based renewable energy and enteric $\mathrm{CH}_{4}$ emissions, respectively. These sources are associated with the animal's physiological functions and are currently challenging to manage. Opportunities for energy conservation and GWP reduction in other segments of the value chain such as the packing and case-ready phases have been adopted by some processors. These include biogas capture from wastewater lagoons at packing plants, increased natural gas use in lieu of fuel oil, packaging optimizations, and improvements in water use efficiency.

The restaurant, case-ready, and retail phases contributed more than $90 \%$ of the total ODP. This is attributed to halogenated hydrocarbons used in refrigeration and pre-chain emissions from the production of LDPE and vinyl gloves used in the restaurant phase.

This study provides a benchmark for a more comprehensive and descriptive national beef LCA. Ongoing studies are gathering information on region-specific feed and cattle management practices, which provide a basis for a more extensive evaluation of cattle production throughout the USA. These more comprehensive data will be used along with the packing, case-ready, retail, and consumer data to better define a national LCA of beef.

Open Access This article is distributed under the terms of the Creative Commons Attribution 4.0 International License (http:// creativecommons.org/licenses/by/4.0/), which permits unrestricted use, distribution, and reproduction in any medium, provided you give appropriate credit to the original author(s) and the source, provide a link to the Creative Commons license, and indicate if changes were made.

\section{References}

AHAM (2011) Average household refrigerator energy use, volume, and price over time. Association of Home Appliance Manufacturers, Washington, D.C. http://www.appliance-standards.org/sites/default/ files/Refrigerator\%20Graph July 2011.PDF. Accessed 29 May 2015

Asem-Hiablie S, Rotz CA, Stout R, Dillon J, Stackhouse-Lawson K (2015) Management characteristics of cow-calf, stocker, and finishing operations in Kansas, Oklahoma, and Texas. Prof Anim Sci 31(1):1-10

Asem-Hiablie S, Rotz CA, Stout R, Stackhouse-Lawson K (2016) Management characteristics of beef cattle production in the Northern Plains and Midwest regions of the United States. Prof Anim Sci 32:736-749

Asem-Hiablie S, Rotz CA, Stout R, Fisher K (2017) Management characteristics of beef cattle production in the western United States. Prof Anim Sci 33:461-471

BASF (2013a) Submission for verification of Eco-efficiency Analysis Under NSF Protocol P352, Part A. U.S. Beef -Phase 1 Ecoefficiency Analysis. BASF Corporation, Florham Park http://www. nsf.org/newsroom_pdf/BASF_NCBA_US_Beef_Industry_ Phase1_may2013.pdf. Accessed 09 June 2017

BASF (2013b) More sustainable beef optimization project phase 1 final report. BASF Corporation, Florham Park http://www. beefissuesquarterly.com/CMDocs/BeefResearch/Sustainability\% 20Completed $\% 20$ Project $\% 20$ Summaries/NCBA $\% 20$ Phase $\% 201 \%$ 20Final\%20Report_Amended\%20with\%20NSF\%20Verified $\%$ 20Report_for_posting_draft\%20WM_KS.pdf. Accessed 09 November $201 \overline{7}$ 
BASF (2015) Submission for verification of Eco-Efficiency Analysis under NSF Protocol P352, Part B. U.S. beef - Phase 2 EcoEfficiency Analysis. BASF Corporation, Florham Park http:// www.beefissuesquarterly.com/CMDocs/BeefResearch/ Sustainability $\% 20$ Completed $\% 20$ Project $\% 20$ Summaries/BASF NCBA\%20US\%20Beef\%20Industry\%20Phase2_\%20NSF\% 20EEA\%20Analysis\%20Report_FINAL.pdf. Accessed 18 April 2015

Belflower JB, Bernard JK, Gattie DK, Hancock DW, Risse LM, Rotz CA (2012) A case study of the potential environmental impacts of different dairy production systems in Georgia. Agric Syst 108:84-93. https://doi.org/10.1016/j.agsy.2012.01.005

Bonnardeaux J (2007) Potential uses for distillers grains. Department of Agriculture and Food. Government of Western Australia, South Perth $15 \mathrm{pp}$

Boustead LCI database (2005) Ver. 5.1.2600.2180. Boustead Consulting Ltd., Horsham

BP (2012) BP statistical review of world energy. BP, London https:// www.bp.com/en/global/corporate/energy-economics/statisticalreview-of-world-energy/downloads.html. Accessed 03 January 2018

Capper JL (2011) The environmental impact of beef production in the United States: 1977 compared with 2007. J Anim Sci 89(12):42494261

Chianese DS, Rotz CA, Richard TL (2009a) Simulation of carbon dioxide emissions from dairy farms to assess greenhouse gas reduction strategies. Trans ASABE 52:1301-1312

Chianese DS, Rotz CA, Richard TL (2009b) Simulation of methane emissions from dairy farms to assess greenhouse gas reduction strategies. Trans ASABE 52:1313-1323

Corson MS, Rotz CA, Skinner RH, Sanderson MA (2007) Adaptation and evaluation of the integrated farm system model to simulate temperate multiple-species pastures. Agric Syst 94:502-508

Deak A, Hall MH, Sanderson MA, Rotz A, Corson M (2010) Wholefarm evaluation of forage mixtures and grazing strategies. Agron J 102:1201-1209

Dudley QM, Liska AJ, Watson AK, Erickson GE (2014) Uncertainties in life cycle greenhouse gas emissions from US beef cattle. J Clean Prod 75:31-39

FMI (2012) Supermarket sales: supermarket sales by department- - percent of total supermarket sales. Food Marketing Institute. http:// www.fmi.org/docs/facts-figures/grocerydept.pdf?sfvrsn $=2$. Accessed 29 May 2015

Forster P, Ramaswamy V, Artaxo P, Berntsen T, Betts R, Fahey DW, Haywood J, Lean J, Lowe DC, Myhre G, Nganga J, Prinn R, Raga G, Schulz M, Van Dorland R (2007) Changes in atmospheric constituents and in radiative forcing. In: Solomon S, Qin D, Manning M, Chen Z, Marquis M, Averyt KB, Tignor M, Miller HL (eds) Climate change 2007: the physical science basis. Contribution of working group I to the fourth assessment report of the intergovernmental panel on climate change. Cambridge University Press, Cambridge, pp 129-234

Freiermuth R (2006) Modell zur Berechnung der Schwermetall-flüsse in der Landwirtschaftlichen Ökobilanz. SALCA-Schwermetall. Agroscope, Zurich http://www.agroscope.admin.ch/oekobilanzen/ 01199/08185/index.html?lang=en. Accessed 29 May 2015

Frischknecht R, Jungbluth N, Althaus HJ, Doka G, Dones R, Heck T, Hellweg S, Hischier R, Nemecek T, Rebitzer G, Spielmann M (2005) The ecoinvent database: overview and methodological framework. Int J Life Cycle Assess 10:3-9

Ghafoori E, Flynn PC, Checkel MD (2006) Global warming impact of electricity generation from beef cattle manure: a life cycle assessment study. Int J Green Energy 3:257-270

Ghebremichael LT, Watzin MC (2011) Identifying and controlling critical sources of farm phosphorus imbalances for Vermont dairy farms. Agric Syst 104:551-561
Guinée JB, Gorrée M, Heijungs R, Huppes G, Kleijn R, de Koning A, van Oers L, Sleeswijk AW, Suh S, de Haes HAU, de Bruijn H, van Duin R, Huijbregts MAJ (2002) Handbook on life cycle assessment. Operational guide to the ISO standards. I: LCA in perspective. IIa: Guide. IIb: Operational annex. III: Scientific background. Kluwer Academic Publishers, Dordrecht ISBN 1-4020-0228-9. http://cml. leiden.edu/research/industrialecology/researchprojects/finished/ new-dutch-lca-guide.html\#reports-in-the-english-language-lastupdate-3-july-2002. Accessed 05232015

Heijungs R, Guinée JB, Huppes G, Lankreijer RM, Udo de Haes HA, Wegener Sleeswijk A, Ansems AMM, Eggels PG, van Duin R, de Goede HP (1992) Environmental life cycle assessment of products: guide and backgrounds (Part 1). CML, Leiden https://openaccess. leidenuniv.nl/handle/1887/8061. Accessed 05292015

ICF Consulting (2005) Revised draft analysis of U.S. commercial supermarket refrigeration systems. Prepared for the U.S. EPA stratospheric protection division. https://www.epa.gov/sites/production/files/ documents/EPASupermarketReport_PUBLIC_30Nov05.pdf Accessed 29 May 2015

IPCC (2006) Guidelines for national greenhouse inventories, Volume 4. Chapter 11: $\mathrm{N}_{2} \mathrm{O}$ emissions from managed soils, and $\mathrm{CO}_{2}$ emissions from lime and urea application. http://www.ipcc-nggip.iges.or.jp/ public/2006gl/pdf/4_Volume4/V4_11_Ch11_N2O\&CO2.pdf Accessed 29 May $201 \overline{5}$

ISO (2006a) ISO 14040: environmental management - life cycle assessment - principles and framework. ISO, Geneva http://wwwisoorg/ iso/catalogue_detail?csnumber $=37456$ Accessed 29 June 2015

ISO (2006b) ISO 14044: Environmental management-life cycle assessment-requirements and guidelines. ISO, Geneva http://www.iso. org/iso/catalogue_detail?csnumber=38498. Accessed 29 June 2015

ISO (2012) ISO 14045: Environmental management - eco-efficiency assessment of product systems - principles, requirements and guidelines. ISO, Geneva http://www.iso.org/iso/catalogue_detail? csnumber=38498. Accessed 06292015

Koellner T, Scholz R (2008) Assessment of land use impacts on the natural environment. Int J Life Cycle Assess 13:32-48

Landsiedel R, Saling P (2002) Assessment of toxicological risks for life cycle assessment and eco-efficiency analysis. Int J Life Cycle Assess 7:261-268

Lory JA, Massey RE, Fulhage CD, Shannon MD, Belyea RL, Zulovich JM (2008) Comparing the feed, fertilizer, and fuel value of distiller's grains. Crop Manag 7(1). https://doi.org/10.1094/CM-2008-042801-RV

Lupo CD, Clay DE, Benning JL, Stone JJ (2013) Life-cycle assessment of the beef cattle production system for the northern great plains, USA. J Environ Qual 42:1386-1394

Meat Solutions, Inc. (2014) Technomic foodservice volumetric study; Freshlook/IRI categorized by VMMeat system; meat solutions annual beef consumption report, prepared for the beef checkoff. Unpublished internal document

Pelletier N, Pirog R, Rasmussen R (2010) Comparative life cycle environmental impacts of three beef production strategies in the upper Midwestern United States. Int J Life Cycle Assess 103:380-389

Pfister S, Koehler A, Hellweg S (2009) Assessing the environmental impacts of freshwater consumption in LCA. Environ Sci Technol 43:4098-4104

Roop DJ, Shrestha DS, Saul DA, Newman S (2014) Cradle-to-gate life cycle assessment of regionally produced beef in the northwestern US. Trans ASABE 57:927-935

Rotz CA, Oenema J, van Keulen H (2006) Whole farm management to reduce nutrient losses from dairy farms: a simulation study. Appl Eng Agric 22(5):773-784

Rotz CA, Montes F, Chianese DS (2010) The carbon footprint of dairy production systems through partial life cycle assessment. J Dairy Sci 93:1266-1282 
Rotz CA, Corson MS, Chianese DS, Montes F, Hafner SD, Coiner CU (2012) Integrated farm system model: reference manual. University Park, USDA Agricultural Research Service http://www.ars.usda. gov/SP2UserFiles/Place/19020000/ifsmreference.pdf. Accessed 29 May 2015

Rotz CA, Isenberg BJ, Stackhouse-Lawson KR, Pollak EJ (2013) A simulation-based approach for evaluating and comparing the environmental footprints of beef production systems. J Anim Sci 91: $5427-5437$

Rotz CA, Asem-Hiablie S, Dillon J, Bonifacio H (2015) Cradle-to-farm gate environmental footprints of beef cattle production in Kansas, Oklahoma, and Texas. J Anim Sci 93:2509-2519

Salim J, Dillon C, Saghaian S, Hancock D (2005) Economic response of site-specific management practices on alfalfa production quantity and quality. In: Cox S (ed) Precision livestock farming '05: proceedings of the 2nd European conference on precision livestock farming June 9-12 2005. Wageningen Academic Publishers, Uppsala, pp 241-247

Saling P, Kicherer A, Dittrich-Krämer B, Wittlinger R, Zombik W, Schmidt I, Schrott W, Schmidt S (2002) Eco-efficiency analysis by BASF: the method. Int J Life Cycle Assess 7:203-218

Sedorovich DM, Rotz CA, Vadas PA, Harmel RD (2007) Simulating management effects on phosphorus loss from farming systems. Trans ASABE 50:1443-1453

Solley WB, Pierce RR, Perlman HA (1998) Estimated use of water in the United States in 1995 U.S. Geological Survey Circular 1200 U.S. Dept. of the Interior, U.S. Geological Survey, Branch of Information Services

Stackhouse KR, Rotz CA, Oltjen JW, Mitloehner FM (2012) Growthpromoting technologies decrease the carbon footprint, ammonia emissions, and costs of California beef production systems. J Anim Sci 90:4656-4665

Stackhouse-Lawson KR, Rotz CA, Oltjen JW, Mitloehner FM (2012) Carbon footprint and ammonia emissions of California beef production systems. J Anim Sci 90:4641-4655

Uhlman BW, Saling P (2010) Measuring and communicating sustainability through eco-efficiency analysis. Chem Eng Prog 106:17-26

USDA-ERS (2005) Daily intake of food at home and away from home: 2003-2004. USDA Economic Research Service. http://www. ersusdagov/data-products/food-consumption-and-nutrientintakesaspx. Accessed 29 May 2015

USDA-ERS (2012a) Loss-adjusted food availability for meat, poultry, fish, eggs, and nuts. USDA Economic Research Service. http:// www.ers.usda.gov/data-products/food-availability-(per-capita)data-system/.aspx. Accessed 29 May 2015
USDA-ERS (2012b) Food availability dataset. USDA Economic Research Service. http://wwwersusdagov/data-products/ commodity-consumption-by-population-characteristicsaspx. Assessed 28 April 2015

USDA-ERS (2017) Feed grains data: yearbook tables. USDA Economic Research Service. http://www.ers.usda.gov/data-products/feedgrains-database/feed-grains-yearbook-tables.aspx. Accessed 25 October 2017

USDA-FAS (2015) Summary: major traders and US trade of beef, pork, and poultry. USDA Foreign Agricultural Service. http://apps.fas. usda.gov/psdonline/circulars/livestock_poultry.pdf. Assessed 28 April 2015

USDOT (2011) 2009 National household travel survey. US Department of Transportation. http://nhts.ornl.gov/2009/pub/stt.pdf. Accessed 29 May 2015

USEIA (2005) 2005 Residential consumption energy survey (RECS). US Energy Information Administration http://wwweiagov/ consumption/residential/data/2005/. Accessed 29 May 2015

USEPA (2010) Municipal solid waste generation, recycling, and disposal in the United States: facts and figures for 2010. US Environmental Protection Agency. http://www.nrc.gov/docs/ML1409/ ML14094A389.pdf. Accessed 29 May 2015

USEPA (2011) Profile of an average U.S. supermarket's greenhouse gas impacts from refrigeration leaks compared to electricity consumption. US Environmental Protection Agency. https://www.epa.gov/ sites/production/files/documents/gc_averagestoreprofile_final_ june_2011_revised_1.pdf. Accessed 09 January, 2018

USEPA (2012) Supermarkets: an overview of energy use and energy efficiency opportunities. US Environmental Protection Agency. https:/www.energystar.gov/sites/default/files/buildings/tools/SPP\% 20Sales $\% 20$ Flyer $\% 20$ for $\% 20$ Supermarkets $\% 20$ and $\% 20$ Grocery $\%$ 20Stores.pdf. Accessed 29 May 2015

USGS (2012) Mineral commodity summaries 2012: U.S. Geological Survey. https://minerals.usgs.gov/minerals/pubs/mcs/2012/ mcs2012.pdf. Accessed 05 Jan 2018

Waldrip HM, Rotz CA, Hafner SD, Todd RW, Cole NA (2014) Processbased modeling of ammonia emission from beef cattle feedyards with the integrated farm systems model. J Environ Qual 43:11591168

Wiedemann S, McGahan E, Murphy C, Yan MJ, Henry B, Thoma G, Ledgard S (2015) Environmental impacts and resource use of Australian beef and lamb exported to the USA determined using life cycle assessment. J Clean Prod 94:67-75 